\title{
ANALISIS FAKTOR-FAKTOR PENYEBAB KESULITAN BELAJAR SISWA PADA MATA PELAJARAN AKUNTANSI
}

\author{
Fitri Nurlaili $^{1)}$, Nely Hartika ${ }^{2)}$, Triana Sri Handayani ${ }^{3)}$ \\ Universitas Banten Jaya \\ Serang, Indonesia \\ fitrinurlaili@unbaja.ac.id ${ }^{1)}$,nelyhartika@unbaja.ac.id ${ }^{2)}$, trianasrihandayani@unbaja.ac.id ${ }^{3)}$
}

\begin{abstract}
This study aimed to: (1) to find out Internal factors that influence student learning difficulties in accounting subjects (2) To find out any external factors that influence student learning difficulties in accounting subjects;(3) To find out dominant factors influence the causes of learning difficulties in accounting subjects. This research method was quantitative research. The population in this study were all students of class XI Accounting in the odd semester of state vocational high school (SMKN) in Serang City. The validity of the questionnaire instrument was performed by item analysis used the Product Moment correlation formula and the reliability test used the Cronbach's Alpha formula. The data analysis technique used factorial analysis Confirmatory factor analysis model. The results of this study indicated that: the biggest internal factor that causes the learning difficulties for learners was (1) a physical factor with eigenvalue of 3.735 and a variance value of 19,659\% (2) the biggest external factor that caused the learning difficulties were family factors with an eigenvalue of 3.735 and a variance value of $19.6 \%$.
\end{abstract}

Keywords: Learning Difficulties, internal factors, external factors, Confirmatory Factor Analysis

\section{A. PENDAhULUAN}

Peningkatan kualitas Pendidikan akan meningkatkan kualitas sumber daya manusia yang diharapkan akan menentukan kemajuan suatu bangsa. Kualitas Pendidikan salah satunya ditentukan oleh proses belajar.

"Belajar ialah suatu proses usaha yang dilakukan seseorang untuk memperoleh suatu perubahan tingkah laku yang baru secara keseluruhan, sebagai hasil pengalamannya sendiri dalam interaksi dengan lingkungannya"( Slameto, 2013: 2), pada kegiatan belajar siswa mengalami sendiri proses dari tidak tahu menjadi tahu, dari tidak terampil menjadi terampil.

Namun proses belajar setiap siswa tidak selamanya sesuai dengan tujuan pembelajaran yang ditetapkan, karena setiap individu memiliki potensi yang berbeda, siswa terkadang cepat memahami penjelasan guru mengenai materi yang diajarkan namun tidak menutup kemungkinan membutuhkan waktu yang lebih lama dalam belajar. 
Hasil belajar yang baik merupakan harapan semua pihak namun pada kenyataannya tidak semua siswa memperoleh hasil belajar yang diharapkan, dalam proses pembelajaran siswa terkadang mengalami kegagalan dalam memperoleh hasil belajar yang diinginkan dikarenakan mengalami kesulitan dalam memahami materi yang diberikan guru

Kesulitan belajar yang didefinisikan oleh The United States Office of Education (USOE) 'kesulitan belajar adalah suatu gangguan dalam satu atau lebih dari proses psikologis dasar yang mencakup pemahaman dan penggunaan bahasa ajaran atau tulisan'. (Kompri, 2017: 176). Kesulitan belajar dapat terjadi apabila siswa tidak mampu mengaitkan pengetahuan baru dan pengetahuan yang sudah dimiliki sehingga menimbulkan ketidakpahaman terhadap suatu pelajaran ( Caryono dan Suhartono, 2012), Kesulitan belajar dapat berupa learning disorder, learning disabilities, learning disfunction, under archiever, dan slow learner (Kompri, 2017)

Kesulitan belajar merupakan perbedaan tingkah laku yang dialami peserta didik dalam menerima atau menyerap pelajaran sehingga peserta didik tidak dapat belajar secara wajar yang disebabkan oleh adanya ancaman, hambatan ataupun gangguan dalam belajar, gejala dari kesulitan belajar selain dari prestasi belajar yang rendah dapat diketahui dari hasil yang diperoleh siswa tidak sesuai dengan usaha yang dilakukan, lambat dalam mengerjakan tugas, memiliki sikap tidak wajar seperti acuh dan tingkah menyimpang seperti membolos, mengasingkan diri dan tidak mau bekerja sama.

Ahmadi dan Supriyono (2013: 78) menyatakan bahwa "faktor- faktor penyebab kesulitan belajar dapat digolongkan menjadi dua golongan, yaitu faktor intern (faktor dari dalam diri manusia itu sendiri) dan faktor ekstern (faktor dari luar manusia)". faktor intern meliputi faktor faktor fisiologi dan faktor psikologi. Sedangkan faktor ekstern meliputi faktor keluarga, faktor sekolah dan faktor mass media dan lingkungan sosial.

Senada Slameto (2013) menjelaskan bahwa faktor intern penyebab kesulitan belajar adalah faktor jasmani, faktor psikologis dan faktor kelelahan, sedangkan factor ekstern disebabkan oleh factor keluarga, factor sekolah dan factor masyarakat.

Mata pelajaran akuntansi merupakan salah satu mata pelajaran yang wajib ditempuh oleh peserta didik jurusan akuntansi namun "pelajaran akuntansi dirasa sulit, dan juga siswa kurang memahami materi dalam proses belajarmengajar sehingga membuat siswa 
membutuhkan waktu lama dalam mengerjakan soal akuntansi, yang akhirnya juga berdampak pada nilai yang diperoleh siswa menjadi rendah. (Rahmawati, 2019:19), mata pelajaran akuntansi dirasa memiliki tingkat kesulitan lebih tinggi dibanding mata pelajaran lain.

\section{B. METODE PENELITIAN}

Metode penelitian yang digunakan adalah kuantitatif deskriptif dengan populasi 71 siswa, Adapun Teknik pengumpulan data menggunakan kuesioner dokumentasi, serta studi kepustakaan. Alat ukur yang digunakan adalah skala likert, keabsahan instrument dilakukan dengan uji validitas dan reliabilitas. Adapun Teknik analisis data yang digunakan adalah analisis faktor konfirmatori dengan tahapan:

1. Menentukan item yang dianalisis,

2. Menguji item yang ditentukan,

3. Melakukan factoring dan rotasi factor

4. Intepretasi factor yang terbentuk

\section{HASIL DAN PEMBAHASAN}

Penelitian dilakukan di SMK $\mathrm{X}$ dengan instrument penelitian berupa kuesioner berbentuk rating scale dengan menggunakan skala likert dengan rentang 1-4. Untuk mengetahui kualitas kuesioner sebelum disebarkan dilakukan uji validitas dan reliabilitas kepada 30 responden. Butir pernyataan sebanyak 20 butir untuk faktor internal dan 25 butir pernyataan faktor eksternal kesulitan belajar

Uji validitas digunakan untuk mengetahui tingkat kemampuan suatu instrumen untuk mengungkapkan sesuatu yang akan diukur oleh instrumen. Instrument dinyatakan valid apabila $\mathrm{r}_{\text {hitung }}>$ $r_{\text {tabel. }} r_{\text {tabel }}$ pada penelitian ini adalah 0,361 . Hasil uji validitas menunjukkan bahwa 16 butir pernyataan factor internal kesulitan belajar dinyatakan valid dan 20 butir pernyataan factor eksternal valid

Kualitas kuesioner juga diketahui melalui uji reliabilitas yaitu uji yang menunjukkan sejauh mana suatu alat ukur bisa diandalkan dan tetap konsisten bila dilakukan pengukuran ulang. Uji reliabilitas dilakukan menggunakan metode alpha Cronbach dan dikatakan reliabel apabila mempunyai nilai alpha lebih dari 0,6

Tabel 1: Hasil Uji Reliabilitas

\begin{tabular}{lllll}
\hline No & Var & r & Realibilitas & Ket \\
& & Cronbach \\
& & & \\
\hline 1 & Flpha & & \\
& internal & & 0,60 & Realibel \\
2 & Faktor & 0,861 & 0,60 & Realibel \\
& eksternal & & & \\
\hline
\end{tabular}

Sumber: Data Primer yang diolah 2019

Berdasarkan hasil uji reliabilitas dinyatakan bahwa seluruh variabel memiliki konsistensi yang sangat kuat ketika digunakan untuk meneliti kembali 
Setelah dilakukan uji instrument maka kuesioner sudah dapat disebarkan kepada responden, kuesioner yang disebar pada penelitian ini berjumlah 71 sesuai dengan jumlah populasi siswa kelas XI SMK X tahun ajaran 2018/2019. Analisis data yang digunakan dalam penelitian ini adalah analisis faktor konfirmatori dengan hasil:

\section{Faktor Internal}

a. Menentukan item yang dianalisis Jumlah item pernyataan yang akan diuji dalam analisis factor adalah 16 item

b. Menguji item yang telah ditentukan Item pernyataan dianalisis menggunakan Kaiser-Mayer-Olkin (KMO), Diperoleh nilai 0,568 , Uji KMO dinyatakan layak dengan kriteria $\mathrm{KMO}>0,5$. Dengan demikian item-item dalam penelitian ini telah sesuai dengan ketentuan.

Langkah selanjutnya adalah Measure of Sampling Adequency (MSA) Untuk dapat diproses lebih lanjut setiap item harus memiliki nilai MSA > 0,5. Pada tahap ini terdapat 4 item pernyataan yang gugur karena memiliki nilai $<0,05$. Pengujian dilanjutkan dengan Kaiser-Mayer-Olkin (KMO) tahap 2 yang menyebabkan perubahan nilai menjadi 0,629 dilanjutkan kembali dengan uji Measure of Sampling Adequency (MSA) dengan hasil 12 item pernyataan semua memiliki nilai $<0,5$

c. Melakukan factoring dan rotasi Proses ekstraksi yang digunakan adalah principle component analysis. Yang akan menghasilkan nilai communalities. Nilai akan menunjukkan sejauh mana item yang diukur dapat dijelaskan. Semakin besar communalities maka semakin erat hubungan dengan factor terbentuk. Semua factor pada penelitian ini $<0,5$ sehingga item pernyataan dapat digunakan lebih lanjut

Langkah berikutnya menghitung total variance explained yang digunakan untuk menjelaskan nilai persen dari varians yang mampu dijelaskan oleh banyaknya faktor yang terbentuk. Nilai ini berdasarkan eigenvalue. Eigenvalue untuk dapat menunjukkan kepentingan relative masing-masing faktor harus memiliki nilai di atas 1. Hasil faktoring dalam penelitian ini adalah: 
Tabel 2 Total Variance Explained Faktor Internal

\begin{tabular}{|c|c|c|c|c|c|c|}
\hline \multirow[b]{2}{*}{$\underset{t}{\text { Componen }}$} & \multicolumn{3}{|c|}{ Initial Eigenvalues } & \multicolumn{3}{|c|}{$\begin{array}{c}\text { Extraction Sums of Squared } \\
\text { Loadings }\end{array}$} \\
\hline & Total & $\begin{array}{c}\% \text { of } \\
\text { Variance }\end{array}$ & $\begin{array}{c}\text { Cumulative } \\
\%\end{array}$ & Total & $\begin{array}{c}\% \text { of } \\
\text { Variance }\end{array}$ & $\begin{array}{c}\text { Cumulative } \\
\%\end{array}$ \\
\hline 1 & 2,610 & 21,747 & 21,747 & 2,610 & 21,747 & 21,747 \\
\hline 2 & 1,695 & 14,124 & 35,872 & 1,695 & 14,124 & 35,872 \\
\hline 3 & 1,394 & 11,614 & 47,486 & 1,394 & 11,614 & 47,486 \\
\hline 4 & 1,241 & 10,343 & 57,829 & 1,241 & 10,343 & 57,829 \\
\hline 5 & 868 & 7,232 & 65,061 & & & \\
\hline 6 & 829 & 6,906 & 71,968 & & & \\
\hline 7 &, 724 & 6,033 & 78,001 & & & \\
\hline 8 & ,704 & 5,863 & 83,864 & & & \\
\hline 9 & ,581 & 4,845 & 88,709 & & & \\
\hline 10 & ,567 & 4,726 & 93,436 & & & \\
\hline 11 & ,406 & 3,383 & 96,819 & & & \\
\hline 12 & ,382 & 3,181 & 100,000 & & & \\
\hline
\end{tabular}

Sumber: Data yang diolah 2019

Dari tabel di atas diketahui bahwa hanya terbentuk 4 faktor, karena 8 faktor lain memiliki nilai eigenvalue kurang dari 1. Faktor yang terbentuk adalah 4 faktor nilai eigenvalue untuk faktor pertama 2,610 $>1$, faktor kedua sebesar 1,695 > 1, faktor ketiga sebesar 1,394>1, faktor keempat sebesar $1,241>1$
Hasil ekstraksi factor memberikan informasi bahwa terdapat 4 faktor yang menjelaskan $57,8 \%$ varians dari 12 item asli. Korelasi antara variabel-variabel dan factor loading hasil ekstraksi adalah

Tabel 3 Component Matriks ${ }^{a}$ Faktor Internal

\section{Component Matrix ${ }^{\mathrm{a}}$}

\begin{tabular}{clcccc} 
& & \multicolumn{4}{c}{ Component } \\
Item & & 1 & 2 & 3 & 4 \\
\hline J1 & Kondisi tubuh saat belajar akuntansi & $\mathbf{, 3 1 5}$ &,- 471 &,- 492 &, 245 \\
J2 & Rasa pusing ketika belajar akuntansi & $\mathbf{, 6 2 4}$ &, 170 &,- 076 &,- 024 \\
J3 & Berusaha menjaga kesehatan & $\mathbf{, 6 3 0}$ &, 043 &,- 141 &,- 544 \\
J4 & Sering tidak berkonsentrasi saat pelajaran & $\mathbf{, 4 7 2}$ &, 493 &,- 261 &, 024 \\
& akuntansi & & & & \\
\hline
\end{tabular}




\begin{tabular}{|c|c|c|c|c|c|}
\hline J5 & Tidak memiliki kelainan atau cacat tubuh & ,577 &,- 45 & ,153 &,- 273 \\
\hline $\mathrm{P} 1$ & $\begin{array}{l}\text { Mempunyai kesulitan memahami materi } \\
\text { akuntansi }\end{array}$ & ,475 & ,182 &,- 574 & ,325 \\
\hline $\mathrm{P} 2$ & Sikap saat belajar akuntansi &, 583 &,- 413 &, 115 &,- 241 \\
\hline $\mathrm{P} 3$ & Mencatat materi akuntansi &, 452 &, 249 & ,610 &,- 047 \\
\hline P4 & $\begin{array}{l}\text { Bertanya pada guru saat tidak dapat } \\
\text { menyelesaikan soal akuntansi }\end{array}$ & ,363 &,- 227 & ,494 & ,416 \\
\hline P8 & Mempersiapkan materi sebelum pelajaran & ,371 &,- 149 & ,182 & ,680 \\
\hline P9 & $\begin{array}{l}\text { Sering melakukan system kebut semalem } \\
\text { (SKS) }\end{array}$ & ,346 & ,443 &,- 033 & ,087 \\
\hline K3 & Pelajaran olahraga membuat kelelahan &, 102 & 679 & ,204 & 029 \\
\hline
\end{tabular}

Sumber: Data Primer diolah 2019

Hasil pemfaktoran dalam tabel 3 belum dapat terintepretasikan karena itemitem yang ada hanya mengumpul pada satu atau belum menyeluruh dan merata pada seluruh faktor. Untuk itu perlu dilakukan rotasi. Rotasi faktor bertujuan untuk mendapatkan tampilan data yang lebih jelas dari nilai loading setiap item terhadap faktor-faktor yang ada. Interprestasi ini didasarkan pada nilai loading yang terbesar dari masing-masing item terhadap faktorfaktor yang ada.

Tabel 4 Rotated Component Matrix ${ }^{a}$ Faktor Internal

\begin{tabular}{clcccc}
\hline & & \multicolumn{3}{c}{ Component } \\
Item & & $\mathbf{1}$ & $\mathbf{2}$ & $\mathbf{3}$ & $\mathbf{4}$ \\
\hline J1 & Kondisi tubuh saat belajar akuntansi &, 215 &, 080 & $\mathbf{, 7 3 7}$ &, 163 \\
J2 & Rasa pusing ketika belajar akuntansi &, 367 & $\mathbf{, 5 2 3}$ &, 008 &, 127 \\
J3 & Berusaha menjaga kesehatan & $\mathbf{7 0 0}$ &, 387 &,- 031 &,- 273 \\
& Sering tidak berkonsentrasi saat pelajaran & & & & \\
J4 & akuntansi &, 068 & $\mathbf{, 7 2 5}$ &,- 019 &,- 054 \\
J5 & Tidak Memiliki kelainan atau cacat tubuh & $\mathbf{7 7 2}$ &,- 051 &, 084 &, 170 \\
& Mempunyai kesulitan memahami materi & & & & \\
P1 & akuntansi &,- 009 & $\mathbf{, 6 7 0}$ &, 486 &, 096 \\
P2 & Sikap saat belajar akuntansi & $\mathbf{, 7 3 7}$ &,- 004 &, 104 &, 169 \\
P3 & Mencatat materi akuntansi &, 329 &, 223 &,- 590 & $\mathbf{3 6 6}$ \\
& Bertanya pada guru saat tidak dapat & & & & \\
P4 & menyelesaikan soal akuntansi &, 200 &,- 050 &,- 108 & $\mathbf{, 7 3 9}$ \\
P8 & Mempersiapkan materi sebelum pelajaran &,- 019 &, 158 &, 174 & $\mathbf{, 7 7 4}$ \\
& Sering melakukan sistem kebut semalem & & & & \\
P9 & (SKS) &, 000 & $\mathbf{, 5 4 2}$ &,- 160 &, 074 \\
K3 & Pelajaran olahraga membuat kelelahan &,- 205 & $\mathbf{, 4 6 1}$ &,- 509 &, 007 \\
\hline
\end{tabular}

Sumber: Data primer diolah 2019 
d. Intepretasi hasil

Intepretasi hasil dilakukan dengan melihat nilai factor loading yang terdapat dalam matrik factor. Factor loading merupakan angka yang menunjukkan besarnya korelasi antara variabel dengan factor yang terbentuk. Berdasarkan intepretasi dari matrik faktor diperoleh hasil sebagai berikut:

\section{Tabel 5 Faktor 1}

\begin{tabular}{lll}
\hline Variabel & Pernyataan & Bobot Variabel \\
\hline J3 & Berusaha menjaga kesehatan & $\mathbf{, 7 0 0}$ \\
J5 & Tidak Memiliki kelainan atau cacat tubuh & $\mathbf{, 7 7 2}$ \\
P2 & Sikap saat belajar akuntansi & $\mathbf{, 7 3 7}$ \\
\hline
\end{tabular}

Sumber: Data Primer yang diolah 2019

Dari tabel diatas diketahui bobot paling besar dari faktor 1 adalah J5,tidak memiliki kelainan atau cacat tubuh, variabel ini memiliki factor loading sebesar 0,772 , faktor ini memberikan sumbangan varians sebesar $21,75 \%$

Tabel 6 Faktor 2

\begin{tabular}{lll}
\hline Variabel & Pernyataan & Bobot Variabel \\
\hline J2 & Rasa pusing ketika belajar akuntansi &, $\mathbf{5 2 3}$ \\
J4 & Sering tidak berkonsentrasi saat pelajaran akuntansi & $\mathbf{, 7 2 5}$ \\
P1 & Mempunyai kesulitan memahami materi akuntansi &, 670 \\
P9 & Sering melakukan sistem kebut semalem (SKS) &, 542 \\
K3 & Pelajaran olahraga membuat kelelahan &, 461 \\
\hline
\end{tabular}

Sumber: Data Primer yang diolah 2019

Dari tabel diatas diketahui bobot paling sebesar $14,12 \%$

besar dari faktor 2 adalah J4, Sering

tidak berkonsentrasi saat pelajaran akuntansi, variabel ini memiliki factor loading sebesar 0,725 , faktor ini memberikan sumbangan varians 
Tabel 7 Faktor 3

\begin{tabular}{lll}
\hline Variabel & Pernyataan & Bobot Variabel \\
\hline J1 & Kondisi tubuh saat belajar akuntansi & 0,737
\end{tabular}

Sumber: Data Primer yang diolah 2019

Dari tabel diatas diketahui bobot paling besar dari faktor 3 adalah $\mathrm{J} 1$, , variabel ini memiliki factor loading sebesar 0,737, faktor ini memberikan sumbangan varians sebesar $11,61 \%$

Tabel 8 Faktor 4

\begin{tabular}{lll}
\hline Variabel & Pernyataan & Bobot Variabel \\
\hline P3 & Mencatat materi akuntansi & $\mathbf{3 6 6}$ \\
P4 & Bertanya pada guru saat tidak dapat & $\mathbf{, 7 3 9}$ \\
& menyelesaikan soal akuntansi & \\
P8 & Mempersiapkan materi sebelum pelajaran & $\mathbf{, 7 7 4}$ \\
\hline
\end{tabular}

Sumber: Data Primer yang diolah 2019

Dari tabel diatas diketahui bobot paling besar dari faktor 5 adalah P8, Mempersiapkan materi sebelum pelajaran, variabel ini memiliki factor loading sebesar 0,774, faktor ini memberikan sumbangan varians sebesar $10,34 \%$

\section{Faktor eksternal}

a. Menentukan item yang dianalisis Jumlah item pernyataan yang akan diuji dalam analisis factor adalah 20 item

b. Menguji item yang telah ditentukan Item pernyataan dianalisis menggunakan Kaiser-Mayer-Olkin (KMO), Diperoleh nilai 0, 616, yang berarti semua item pernyataan telah sesuai dengan ketentuan.

Langkah selanjutnya adalah Measure of Sampling Adequency (MSA) Untuk dapat diproses lebih lanjut setiap item harus memiliki nilai MSA > 0,5. Pada tahap ini terdapat 1 item pernyataan yang gugur karena memiliki nilai < 0,05. Pengujian dilanjutkan dengan Kaiser-Mayer-Olkin (KMO) tahap 2 yang menyebabkan perubahan nilai menjadi 0,637 dilanjutkan kembali dengan uji Measure of Sampling Adequency (MSA) dengan hasil 19 item pernyataan semua memiliki nilai $<0,5$ 
c. Melakukan factoring dan rotasi

Proses ekstraksi yang digunakan adalah principle component analysis.. Semua factor pada penelitian ini $<0,5$ sehingga item pernyataan dapat digunakan lebih lanjut Langkah selanjutnya adalah menghitung total variance explained yang digunakan untuk menjelaskan nilai persen dari varians yang mampu dijelaskan oleh banyaknya factor yang terbentuk.

Tabel 9 Total Variance Explained Faktor Eksternal

\begin{tabular}{|c|c|c|c|c|c|c|}
\hline \multirow[b]{2}{*}{ Component } & \multicolumn{3}{|c|}{ Initial Eigenvalues } & \multicolumn{3}{|c|}{$\begin{array}{c}\text { Extraction Sums of Squared } \\
\text { Loadings }\end{array}$} \\
\hline & Total & $\begin{array}{c}\% \text { of } \\
\text { Variance }\end{array}$ & $\begin{array}{c}\text { Cumulative } \\
\%\end{array}$ & Total & $\begin{array}{c}\% \text { of } \\
\text { Variance }\end{array}$ & $\begin{array}{c}\text { Cumulative } \\
\%\end{array}$ \\
\hline 1 & 3,735 & 19,659 & 19,659 & 3,735 & 19,659 & 19,659 \\
\hline 2 & 2,408 & 12,676 & 32,335 & 2,408 & 12,676 & 32,335 \\
\hline 3 & 1,955 & 10,289 & 42,624 & 1,955 & 10,289 & 42,624 \\
\hline 4 & 1,363 & 7,174 & 49,798 & 1,363 & 7,174 & 49,798 \\
\hline 5 & 1,181 & 6,214 & 56,012 & 1,181 & 6,214 & 56,012 \\
\hline 6 & 1,143 & 6,013 & 62,025 & 1,143 & 6,013 & 62,025 \\
\hline 7 & 1,000 & 5,263 & 67,288 & & & \\
\hline 8 & ,918 & 4,832 & 72,121 & & & \\
\hline 9 & ,834 & 4,391 & 76,512 & & & \\
\hline 10 & ,760 & 4,000 & 80,512 & & & \\
\hline 11 & ,622 & 3,272 & 83,783 & & & \\
\hline 12 & ,562 & 2,959 & 86,742 & & & \\
\hline 13 & ,510 & 2,682 & 89,425 & & & \\
\hline 14 & ,485 & 2,554 & 91,979 & & & \\
\hline 15 & ,424 & 2,234 & 94,213 & & & \\
\hline 16 & ,380 & 2,002 & 96,215 & & & \\
\hline 17 & ,261 & 1,374 & 97,589 & & & \\
\hline 18 & ,250 & 1,314 & 98,903 & & & \\
\hline 19 & ,208 & 1,097 & 100,000 & & & \\
\hline
\end{tabular}

Extraction Method: Principal Component Analysis.

Sumber: Data primer diolah 2019

Pada tabel di atas dapat dilihat bahwa terdapat (component) 6 faktor yang memenuhi syarat $<1$. eigenvalue untuk faktor pertama sebesar $3,735>1$, faktor kedua sebesar 2,408 > 1, faktor ketiga sebesar 1,955 > 1, keempat sebesar 1,363 
$>1$, faktor kelima sebesar 1,181 > 1, faktor

keenam sebesar $1,143>1,6$ faktor tersebut menjelaskan $62 \%$ dari 19 item pernyataan. Korelasi antara variabelvariabel dan factor loading hasil ekstraksi adalah

Tabel 10 Component Matrix ${ }^{a}$ Faktor Eksternal

\begin{tabular}{|c|c|c|c|c|c|c|c|}
\hline \multirow[b]{2}{*}{ Item } & & \multicolumn{6}{|c|}{ Component } \\
\hline & & 1 & 2 & 3 & 4 & 5 & 6 \\
\hline $\mathrm{K} 2$ & Belajar bersama kakak/adik & ,683 &,- 359 &,- 084 & ,077 &,- 158 & 140 \\
\hline K3 & $\begin{array}{l}\text { Adik suka menjahili ketika } \\
\text { sedang belajar }\end{array}$ &, 445 &,- 028 & ,322 & ,279 & ,319 &,- 377 \\
\hline K4 & $\begin{array}{l}\text { Orang tua jarang bertanya } \\
\text { kegiatan sekolah }\end{array}$ & ,446 & ,107 &,- 154 &,- 549 &,- 154 & ,126 \\
\hline K5 & $\begin{array}{l}\text { Orang tua tidak memberikan } \\
\text { fasilitas yang cukup }\end{array}$ & ,485 &,- 035 &,- 098 &, 036 &,- 437 &,- 101 \\
\hline K7 & $\begin{array}{l}\text { Berusaha memecahkan } \\
\text { masalah }\end{array}$ & ,233 &,- 084 & ,616 &,- 012 &, 040 &,- 220 \\
\hline K8 & Suasana rumah bersih & ,655 & ,352 & ,062 &,- 152 & ,013 &,- 067 \\
\hline K10 & $\begin{array}{l}\text { Lingkungan masyarakat yang } \\
\text { baik }\end{array}$ &, 524 &, 151 & ,423 &,- 309 &, 140 &,- 038 \\
\hline $\mathrm{S} 1$ & Kegiatan belajar mengajar &, 157 &, 471 &,- 288 & ,043 & ,328 &, $\mathbf{4 5 0}$ \\
\hline S2 & Metode pembelajaran & ,442 &, 065 &,- 180 &, 423 &,- 398 &,- 060 \\
\hline S3 & $\begin{array}{l}\text { Memberikan kesempatan } \\
\text { pada peserta didik }\end{array}$ &, 142 & ,670 & ,309 &, 260 &, 042 &, 420 \\
\hline S4 & Memotivasi peserta didik &, 454 & ,366 &,- 197 & ,229 & ,396 &,- 404 \\
\hline S5 & Media pembelajaran & ,408 & ,292 &,- 514 & ,169 &,- 251 & ,015 \\
\hline S6 & Meninggalkan sekolah & ,037 & ,676 &,- 297 &, 087 &, 013 &,- 151 \\
\hline S7 & Gedung sekolah &, 522 &,- 408 &, 138 &, 277 &,- 174 &, 020 \\
\hline
\end{tabular}

Sumber: Data primer diolah 2019

Hasil pemfaktoran pada tabel Component Matriks belum dapat diinterpretasikan, karena item-item yang ada hanya mengumpul pada satu atau belum meyeluruh dan merata pada seluruh faktor, untuk itu perlu dilakukan proses rotasi faktor 
Tabel 11 Rotated Component Matrix ${ }^{a}$ Faktor Eksternal

\begin{tabular}{|c|c|c|c|c|c|c|c|}
\hline \multirow[b]{2}{*}{ Item } & & \multicolumn{6}{|c|}{ Component } \\
\hline & & 1 & 2 & 3 & 4 & 5 & 6 \\
\hline $\mathrm{K} 2$ & Belajar bersama kakak/adik &, 347 &, 554 & ,448 &,- 122 &,- 086 & ,045 \\
\hline K3 & $\begin{array}{l}\text { Adik suka menjahili ketika } \\
\text { sedang belajar }\end{array}$ &, 056 &, 233 & 051 &, 110 &,- 161 & ,726 \\
\hline K4 & $\begin{array}{l}\text { Orang tua tidak memberikan } \\
\text { fasilitas yang cukup }\end{array}$ &, 710 &,- 050 & ,139 &,- 121 &, 117 &,- 147 \\
\hline K5 & Kebersihan rumah &, 283 &, 063 &, $\mathbf{5 8 9}$ &,- 004 &,- 129 &, 018 \\
\hline K7 & $\begin{array}{l}\text { Berusaha memecahkan } \\
\text { masalah }\end{array}$ &, 194 &, 128 &,- 107 & ,355 &,- 420 & ,352 \\
\hline K8 & $\begin{array}{l}\text { Orang tua jarang bertanya } \\
\text { kegiatan sekolah }\end{array}$ &, $\mathbf{5 7 0}$ &,- 005 & ,260 &, 150 & ,200 & ,358 \\
\hline K10 & $\begin{array}{l}\text { Lingkungan masyarakat } \\
\text { yang baik }\end{array}$ &, 617 & ,106 &,- 096 & ,276 &,- 068 & ,334 \\
\hline S1 & Kegiatan belajar mengajar &, 107 & ,069 &,- 056 &, 061 & ,786 & ,015 \\
\hline S2 & Metode pembelajaran &,- 030 &, 130 & ,730 &, 074 & 053 &, 117 \\
\hline S3 & $\begin{array}{l}\text { Memberikan kesempatan } \\
\text { pada peserta didik }\end{array}$ & ,038 &, 004 &, 037 & ,720 &, 528 &, 100 \\
\hline $\mathrm{S} 4$ & Memotivasi peserta didik &, 080 &,- 081 & , 195 &,- 149 & ,335 & ,752 \\
\hline S5 & Media pembelajaran &, 125 &,- 073 & ,632 &,- 153 & ,403 & ,039 \\
\hline S6 & Meninggalkan sekolah &,- 011 &,- 479 & ,220 &, 050 & ,496 & ,224 \\
\hline S7 & Gedung sekolah &, 105 &, 545 & ,400 & ,039 &,- 277 &, 138 \\
\hline S8 & Ruang kelas &,- 143 & ,831 &, 102 &,- 055 &, 052 &, 143 \\
\hline S9 & Cara mengajar guru &, 183 &,- 186 & 059 &, 805 &,- 043 & ,131 \\
\hline M1 & Lingkungan tempat tinggal & ,697 & ,139 &, 158 & ,005 &,- 065 & ,067 \\
\hline M3 & Adanya internet &, 447 &, 651 &,- 076 &,- 144 &, 159 & ,044 \\
\hline M4 & Teman bergaul & ,318 &, 048 &, 112 &,- 613 &, 104 & ,290 \\
\hline
\end{tabular}

Sumber: Data primer diolah 2019

d. Intepretasi hasil

Tabel 12 Faktor 1

\begin{tabular}{lll}
\hline Variabel & Pernyataan & Bobot Variabel \\
\hline K4 & Orang tua jarang bertanya kegiatan sekolah & $\mathbf{, 7 1 0}$ \\
K8 & Kebersihan rumah & $\mathbf{, 5 7 0}$ \\
K10 & Lingkungan masyarakat yang baik & $\mathbf{, 6 1 7}$ \\
\hline
\end{tabular}

Sumber: Data Primer yang diolah 2019

Dari tabel diatas diketahui bobot paling besar dari faktor 1 adalah $\mathrm{K} 4$, orang tua jarang bertanya kegiatan sekolah, faktor ini memberikan sumbangan varians sebesar $19,659 \%$ 
Tabel 13 Faktor 2

\begin{tabular}{lll}
\hline Variabel & Pernyataan & Bobot Variabel \\
\hline K2 & Belajar Bersama kakak/adik & $\mathbf{, 5 5 4}$ \\
S7 & Gedung sekolah & $\mathbf{, 5 4 5}$ \\
S8 & Ruang kelas & $\mathbf{8 3 1}$ \\
M3 & Adanya Internet & $\mathbf{, 6 5 1}$
\end{tabular}

Sumber: Data Primer yang diolah 2019

Dari tabel diatas diketahui bobot paling faktor ini memberikan sumbangan varians besar dari faktor 2 adalah S8, ruang kelas, sebesar $12,67 \%$

Tabel 14 Faktor 3

\begin{tabular}{lll}
\hline Variabel & Pernyataan & Bobot Variabel \\
\hline K5 & Orang tua tidak memberikan fasilitas yang cukup & $\mathbf{, 5 8 9}$ \\
S2 & Metode Pembelajaran & $\mathbf{, 7 3 0}$ \\
S6 & Media Pembelajaran & $\mathbf{, 6 3 2}$ \\
\hline
\end{tabular}

Sumber: Data Primer yang diolah 2019

Dari tabel diatas diketahui bobot paling pembelajaran, faktor ini memberikan besar dari faktor 3 adalah S2, metode sumbangan varians sebesar $10,297 \%$

Tabel 15 Faktor 4

\begin{tabular}{lll}
\hline Variabel & Pernyataan & Bobot Variabel \\
\hline S3 & Memberikan kesempatan pada peserta didik & $\mathbf{, 7 2 0}$ \\
S9 & Gaya mengajar guru & $\mathbf{, 8 0 5}$ \\
\hline
\end{tabular}

Sumber: Data Primer yang diolah 2019

Dari tabel diatas diketahui bobot paling besar dari faktor 4 adalah S9, metode pembelajaran, faktor ini memberikan 
Tabel 15 Faktor 5

\begin{tabular}{lll}
\hline Variabel & Pernyataan & Bobot Variabel \\
\hline S1 & Kegiatan belajar mengajar & $\mathbf{, 7 8 6}$
\end{tabular}

Sumber: Data Primer yang diolah 2019

Dari tabel diatas diketahui bobot paling besar dari faktor 5 adalah S1, kegiatan belajar mengajar, faktor ini memberikan sumbangan varians sebesar 6,214\%

Tabel 16 Faktor 6

\begin{tabular}{lll}
\hline Variabel & Pernyataan & Bobot Variabel \\
\hline & Adik suka menjahili ketika sedang belajar &, 726 \\
K3 & & \\
K7 & Berusaha memecahkan masalah &, 352 \\
S4 & Memotivasi peserta didik & .752
\end{tabular}

Sumber: Data Primer yang diolah 2019

Dari tabel diatas diketahui bobot paling besar dari faktor 6 adalah S4, memotivasi peserta didik, faktor ini memberikan sumbangan varians sebesar $6,013 \%$

Kesulitan belajar merupakan salah satu permasalahan yang ada dalam kegiatan pembelajaran, siswa yang mengalami kesulitan belajar biasanya sulit untuk dapat menerima materi pebelajaran dengan baik sehingga hasil belajar tidak sesuai dengan yang diharapkan. Kesulitan belajar bukan hanya berasal dari kemampuan intelegensi, namun seringkali juga disebabkan faktor non intelegensi (Ahmadi dan Supriyono, 2013). Kesulitan belajar dapat berasal dari faktor intern dan ekstern siswa. faktor jasmani, faktor psikologis dan faktor kelelahan, sedangkan factor ekstern disebabkan oleh factor keluarga, factor sekolah dan factor masyarakat

Penelitian mengenai faktor-faktor yang mempengaruhi kesulitan belajar akuntansi ini dilakukan dengan analisis faktor konfirmatori dengan siswa kelas XI SMK X tahun ajaran 2018/2019 sebagai respondennya

Berdasarkan tahap analisis faktor diperoleh hasil bahwa faktor intern yang terdiri atas faktor jasmani, psikologis dan kelelahan mempengaruhi $57 \%$ sedangkan sisanya dijelaskan oleh faktor intern lain yang tidak dijelaskan dalam penelitian 


\section{Tabel 17. Identitas Faktor Internal}

\begin{tabular}{|c|c|c|c|}
\hline Var & Pernyataan & $\begin{array}{l}\text { Factor } \\
\text { Loading }\end{array}$ & Nama Faktor \\
\hline $\mathrm{J} 3$ & Berusaha menjaga kesehatan & ,700 & Jasmani \\
\hline $\mathrm{J} 5$ & $\begin{array}{l}\text { Tidak Memiliki kelainan atau cacat } \\
\text { tubuh }\end{array}$ & ,772 & \\
\hline $\mathrm{P} 2$ & Sikap saat belajar akuntansi & ,737 & \\
\hline $\mathrm{J} 2$ & Rasa pusing ketika belajar akuntansi &, $\mathbf{5 2 3}$ & Kesulitan konsentrasi \\
\hline $\mathrm{J} 4$ & $\begin{array}{l}\text { Sering tidak berkonsentrasi saat } \\
\text { pelajaran akuntansi }\end{array}$ & ,725 & \\
\hline $\mathrm{P} 1$ & $\begin{array}{l}\text { Mempunyai kesulitan memahami } \\
\text { materi akuntansi }\end{array}$ & 670 & \\
\hline P9 & $\begin{array}{l}\text { Sering melakukan sistem kebut } \\
\text { semalem (SKS) }\end{array}$ &, 542 & \\
\hline K3 & $\begin{array}{l}\text { Pelajaran olahraga membuat } \\
\text { kelelahan }\end{array}$ & ,461 & \\
\hline $\mathrm{J} 1$ & Kondisi tubuh saat belajar akuntansi & 0,737 & Kondisi fisik \\
\hline P3 & Mencatat materi akuntansi & ,366 & psikologis \\
\hline P4 & $\begin{array}{l}\text { Bertanya pada guru saat tidak dapat } \\
\text { menyelesaikan soal akuntansi }\end{array}$ &, 739 & \\
\hline P8 & $\begin{array}{l}\text { Mempersiapkan materi sebelum } \\
\text { pelajaran }\end{array}$ & ,774 & \\
\hline
\end{tabular}

Sumber data primer yang diolah 2019

Berdasarkan hasil analisis faktor jasmani peserta didik adalah faktor terbesar mempelihatkan faktor-faktor yang yang mempengaruhi kesulitan belajar mempengaruhi kesulitan belajar mata siswa. Slameto (2013: 54) bahwa " proses pelajaran akuntansi adalah, faktor jasmani, belajar akan terganggu jika kesehatan kesulitan konsentrasi, kondisi fisik dan seseorang terganggu, jadi pentingnya siswa psikologi. Sumbangan varians terbesar selalu menjaga kesehatan tubuh dengan adalah faktor jasmani sebesar $21,7 \%$, Hal mengkonsumsi makanan yang sehat dan ini memperlihatkan bahwa keadaan seimbang agar stamina selalu terjaga". 
Senada oktavianingtyas ( 2013: 23),

"Kondisi fisik yang sehat dan normal dapat memperlancar proses belajar "oleh karena itu apabila kondisi jasmani tidak dalam kondisi prima akan menyebabkan kesulitan belajar pada siswa.
Selain faktor intern faktor ekstern merupakan salah satu penyebab siswa mengalami kesulitan belajar, faktor ekstern terdiri dari faktor keluarga, sekolah dan masyarakat. Pada penelitian ini faktor eksternal mempengaruhi $62 \%$ kesulitan belajar siswa

Tabel 18 Identitas Faktor Eksternal

\begin{tabular}{llll}
\hline Var & Pernyataan & $\begin{array}{l}\text { Factor } \\
\text { Loading }\end{array}$ & Nama Faktor \\
\hline K4 & $\begin{array}{l}\text { Orang tua jarang bertanya kegiatan } \\
\text { sekolah }\end{array}$ & $\mathbf{, 7 1 0}$ & Faktor keluarga \\
K8 & Kebersihan rumah & $\mathbf{5 7 0}$ & \\
K10 & Lingkungan masyarakat yang baik & $\mathbf{, 6 1 7}$ & \\
K2 & Belajar Bersama kakak/adik & $\mathbf{, 5 5 4}$ & Faktor sekolah \\
S7 & Gedung sekolah & $\mathbf{, 5 4 5}$ & \\
S8 & Ruang kelas & $\mathbf{, 8 3 1}$ & \\
M3 & Adanya Internet & $\mathbf{6 5 1}$ & Metode Pembelajaran \\
K5 & Orang tua tidak memberikan fasilitas & $\mathbf{, 5 8 9}$ & \\
& yang cukup & & \\
S2 & Metode Pembelajaran & $\mathbf{7 3 0}$ & \\
S6 & Media Pembelajaran & $\mathbf{6 3 2}$ & Gaya mengajar \\
S3 & Memberikan kesempatan $\quad$ pada & $\mathbf{, 7 2 0}$ & \\
& peserta didik & $\mathbf{8 0 5}$ & Kegiatan belajar mengajar \\
S9 & Gaya mengajar guru & $\mathbf{7 8 6}$ & Motivasi siswa \\
S1 & Kegiatan belajar mengajar &, 726 & \\
& Adik suka menjahili ketika sedang & \\
K3 & belajar &, 352 & \\
K7 & Berusaha memecahkan masalah & $\mathbf{7 5 2}$ & \\
S4 & Memotivasi peserta didik &
\end{tabular}

Sumber Data Primer yang diolah 2019

Berdasarkan hasil analisis faktor mempelihatkan faktor-faktor ekstern yang mempengaruhi kesulitan belajar mata pelajaran akuntansi adalah, faktor keluarga, faktor sekolah, metode pembelajaran, gaya mengajar, kegiatan belajar mengajar dan motivasi siswa. Faktor keluarga memiliki sumbangan varians sebesar 19,569\%, siswa kurang mendapatkan bimbingan dari orang tua pada saat belajar di rumah, hal ini dapat terjadi karena kesadaran orang tua terhadap Pendidikan masih rendah, serta kesibukan orang tua sehingga tidak ada waktu untuk mendampingi anaknya belajar 
PROGRESS

Jurnal Pendidikan, Akuntansi dan Keuangan Universitas Banten Jaya

(Maftukhah,2012: 4-5). Dukungan keluarga sangat dibutuhkan untuk mengatasi kesulitan belajar yang dialami oleh siswa

\section{KESIMPULAN DAN SARAN}

Berdasarkan analisis pada pembahasan dari data diatas, maka dapat ditarik kesimpulan sebagai berikut:

1. Faktor internal yang paling mempengaruhi kesulitan belajar akuntansi adalah adalah Faktor Jasmani dengan nilai eigenvalue sebesar 2,610 dan nilai varians sebesar $21,7 \%$,

2. Faktor eksternal yang menjadi penyebab terbesar kesulitan belajar akuntansi adalah kondisi Keluarga dengan nilai eigenvalue sebesar 3,735 dengan nilai varians sebesar $19,6 \%$.

Berdasarkan kesimpulan yang sudah disampaikan maka disarankan:

1. Bagi siswa hendak terus membiasakan kebiasaan belajar baik ketika berada di sekolah maupun di rumah, dikarenakan faktor internal yang menjadi penyebab terbesar kesulitan belajar akuntansi yaitu faktor dari dalam diri siswa

2. Bagi guru yang merupakan faktor eksternal penyebab kesulitan belajar hendaknya lebih perhatian, kreatif, dan inovatif dalam pelaksanaan pembelajaran serta menyesuaikan kegiatan pembelajaran dengan kebutuhan siswa sehingga proses belajar mengajar akan lebih efektif dan efesien. Selain itu, guru perlu membangun relasi yang baik dengan siswa di dalam kelas maupun di luar kelas sehingga akan terbentuk hubungan yang baik yang akan mendukung proses belajar mengajar di dalam kelas.

3. Bagi orang tua, hendaknya lebih memperhatikan Pendidikan putraputrinya di rumah, memberikan motivasi, dukungan moral serta material

4. Bagi peneliti lain, untuk menambah faktor-faktor lain dan subyek yang diteliti.

\section{REFERENSI}

Ahmadi, Abu \& Supriyono, W (2013). Psikologi Belajar. Jakarta: Rineka Cipta.

Caryono, Suhas\& Suhartono . (2012) Analisis DeskriptifFaktor Penyebab Kesulitan Belajar Mata Pelajaran Matematika di SMA Negeri 8 Purworejo Tahun Pelajaran 2012/2013. Prosiding ISBN:978797-16353-8-7. Diakses 15 Juni 2019. Eprint.uny.ac.id

Kompri. (2017). Belajar Faktor-faktor yang Mempengaruhinya. Yogyakarta: Media Akademi.

Slameto (2013). Belajar dan Faktor-Faktor Yang Mempengaruhi. Jakarta: Rineka Cipta.

Maftukhah, Lina, Harnanik\& St. Sunarto. 
(2012) Faktor-Faktor yang Mempengaruhi Kesulitan Belajar IPS Terpadu Kelas VII di SMP Negeri 1 Plantungan Kabupaten Kendal. Economic Education Analysis Journal Vol 1 No 22012 diakses 15 Juni 2019, dari Journal.unnes. ac.id

Oktavianingtyas, Ervin. ( 2013). Studi Tentang Faktor-Faktor yang Mempengaruhi Prestasi Belajar Mahasiswa Program Studi Pendidikan Matematika FKIP Universitas Jember. Kadikma Vol 4 No 2 2013, diakses 15 Juni 2019, dari jurnal.unej.ac.id

Rahmawati, Tanti \& Fitri Nurlaili (2019). Penelitian Tindakan Kelas Group to Group Exchange. Progress Vol 2 No 12019 .Diakses 12 Maret 2019. Dari e-journal.lppmunbaja.ac.id/progrress 